\title{
Is there enough information to calculate the financial benefits of ergonomics projects?
}

\author{
Pereira da Silva, M..$^{\text {a, }}$, Pruffer, C. ${ }^{\text {b }}$ and Amaral, F. G. ${ }^{a}$ \\ ${ }^{a}$ Production Engineering and Transportation Department, Federal University of Rio Grande do Sul, Av. Osvaldo \\ Aranha 99, $5^{\circ}$ floor, CEP90035-190, Porto Alegre, RS, Brazil \\ ${ }^{\mathrm{b}}$ Human Engineering Group, Department of Production and Systems, University of Minho, 4800-058 Guimarães, \\ Portugal
}

\begin{abstract}
Many authors studied work situations and, mainly, ergonomics projects concerning the financial benefit point of view. At the same time seems to be little information available concerning these financial benefits in manufacturing companies' processes. The aim of this article is to identify if there enough information available within a company to quantify the financial benefits of an ergonomic project. The study was applied on two manufacturing companies, one in Brazil and other in Portugal. A literature review based checklist and a manager interview was applied on each company in order to identify if the information was available and how were been used. The two companies have revealed a good quantity of available information regarding ergonomics benefit calculation. The interviews showed that managers are not aware of the financial savings possibility with investments in ergonomics projects.
\end{abstract}

Keywords: ergonomics, project, financial benefits, information

\section{Introduction}

The scientific literature applies that occupational issues that can be reduced via ergonomics can also generate great financial loss. Researches such as $[3,5$, $10,29]$ focused their work on labor issues and especially the financial impact of ergonomic projects. A research at Malaysia [27] had a great case study of ergonomics performance on electronic components factory whereby the company was able to achieve a value greater than $\$ 580.000 /$ year for scrap and rework reduction plans. However, a study [26] estimates the benefits of Ergonomic intervention on work tools to be $\$ 184.255 /$ year with positive return of investment (ROI) within four months. From an economic point of view, there are enough studies that indicate the positive results to justify improvements on labor conditions within corporations. However, an accurate calculation of any possible financial loss is difficult due to the lack of information and track record of expenses and benefits related to improvements on occupational issues [29]. The increase in publications on the cost-benefit of ergonomics shows the relevance of this subject for scientific research, as well as for manufacturing production practices. At the same time, there is little use of financial information related occupational issues exchangeable reduction through investment in ergonomics $[9,13$, 24].The difficult task of gathering relevant information to identify or anticipate the financial benefits of a project of ergonomics is cited by some authors $[2,7$, $18,28]$. One of the barriers that hinder the calculation of these potential benefits is the lack of information on occupational problems that might justify an intervention to improve. This problem can still be extended by the lack of interest in the subject on the part of managers. There is a question around the possibility of incorporating the financial cost-benefit of ergonomics in the decision-making process for managers. The knowledge of when a decision needs to be made is important to allow the process of collecting information prior to the event and not retrospectively [23].

${ }^{*}$ Corresponding author. E-mail: ergocelo@gmail.com 
The lack of information to feed the cost-benefit analyses of ergonomics can be a reflection of the fact that it generally does not happen in a preventive manner, when it would be easier and cheaper, and is very expensive after the occurrence of an event such as an accident or an occupational disease.

This article aims to identify if there enough information available to properly assess and quantify the benefits expected from investments on ergonomic projects. It will also identify if the information utilized to measure the projects effectiveness is related in any way to production process management.

\section{Literature review}

A systematic literature review was initiated with the goal of gather application studies about the finan- cial impact of ergonomic projects in several organizations. The search was done via Scholar Google, PubMed, Academic Search Premier, CINAHL and specialized journals, such as Ergonomics, Applied Ergonomics e International Journal of Industrial Ergonomics. The search was done using the term ergonomics associated with costs, benefits, finance, information and project. The studies that did not meet the proposed focus (e.g. on the energy cost of a particular activity), or are not the result of a practical application were excluded at this stage.

This approach find 18 studies, which was read by three researches to define the type of information used to calculate the financial benefits of the ergonomics projects. This information and its sources are presented in Table 1.

Table 1

Information about financial benefit of ergonomics projects found. The numbers in the right column represent the studies in the reference section of this paper. The numbers in the left column are linked with the checklist on the results section.

\begin{tabular}{|l|l|l|}
\hline & INFORMATION & STUDIES \\
\hline 1 & Productivity & $\begin{array}{l}1,14,8,26,27,16,19,17,30,15,12, \\
6,27\end{array}$ \\
\hline 2 & Lost work days & $1,21,26,16,5,19,17,12,6$ \\
\hline 3 & Product with errors/rejects or returns & $14,27,30,12$ \\
\hline 4 & Turnover & $1,14,22,26$ \\
\hline 5 & Overtime work & $21,20,14,27$ \\
\hline 6 & Cycle time of tasks & $8,27,30$ \\
\hline 7 & Absenteeism caused by injuries/illness & $1,21,20,14,25,26,16,5,19,17,12$, \\
& Work time loss caused by injuries/illness & 6 \\
\hline 8 & Incidence and severity of injuries and illness & $21,20,25,26,4,19,17,12$ \\
\hline 9 & Incidence of physical pain & $21,20,14,22,25,26,4,19,17,12,6$ \\
\hline 10 & Cost of substandard performance & $20,16,5,19,17,6$ \\
\hline 11 & Rework costs & $27,26,27,19,17,30,6$ \\
\hline 12 & $\begin{array}{l}\text { Cost of injury/illness treatment (medical, exams, medicaments, physio- } \\
\text { therapy, transports) }\end{array}$ & $21,20,22,26,16,4,19,17,12,6$ \\
\hline 13 & Cost of total or partial incapacitation & 26 \\
\hline 14 & Compensation costs & $1,21,14,22,26,16,5,4,19,17,12$, \\
\hline 15 & 6 \\
\hline 16 & Cost of administration processes for new hires & $1,14,26,4,15,12$ \\
\hline 17 & Cost of legal proceedings related to injuries/illness & 25,26 \\
\hline 18 & Training costs of new workers & $1,20,14,26,19,17,30$ \\
\hline & & \\
\hline
\end{tabular}




\section{Methodological procedures}

The study was conducted in two stages. From the results of the systematic review a checklist was drawn up to guide the identification of information available in each organization. To do this, the information utilized were identified in each study of revision, discussed between the researchers and then organized in a checklist format. This list was constructed by contemplating the sources of each kind of information. Only the information that represented, even indirectly, results of an ergonomics project were considered on this research, for example, the cost of rework in task improvement interventions.

The second stage was the application of a structured interview to identify the existence of information that may justify investment in ergonomics projects within the company's management. Therefore, the interview aims to identify how information is used in the company, as well as highlight the existing culture of Ergonomic Management.

Five questions conducted the interview and aimed determine professional characteristics of the respondent as well as the relationship between health and productive system information with ergonomics management. This separation was made to facilitate the understanding the respondent comprehension about the subject.

The main discussion topics found in the studies of the revision served as a basis for interview questions. Before application of the interview, the respondent received information about the theme of the research, its objectives and its purpose.

\section{Results}

As the methodological procedures described, a checklist was prepared based on the information found in the systematic review. Basically, the researchers marked with "YES or NO" the existence of each one of the information on the checklist and wrote down a commentary about it. Managers helped to fill the checklist according to the company's management practices. After that, an interview regarding the main subjects on this study was made with the managers. The study was applied in a large manufacturer of glass containers, located in south of Brazil and in a major paper converting facility located in Portugal.

\subsection{Glass manufacturer}

The first application of the proposed methodology was carried on in a glass containers manufacturer, which has bottles of wine and beer as their main products. The plant was visited by the browser in the first quarter of 2011, where the application of the checklist and interview with managers. The glass manufacturer is linked to a central company in another state where all key information and financial management of the group is process. This group of information that is sent to this central constitutes the biggest concerns of managers of the plant. There are four subgroups: productivity (yield, production speed and time of an exchange of product), quality (scrap, rework and discards), safety (accidents with or without removal, health care and prevention actions) and human resources (absenteeism from various causes, turnover, number of workers and overtime).

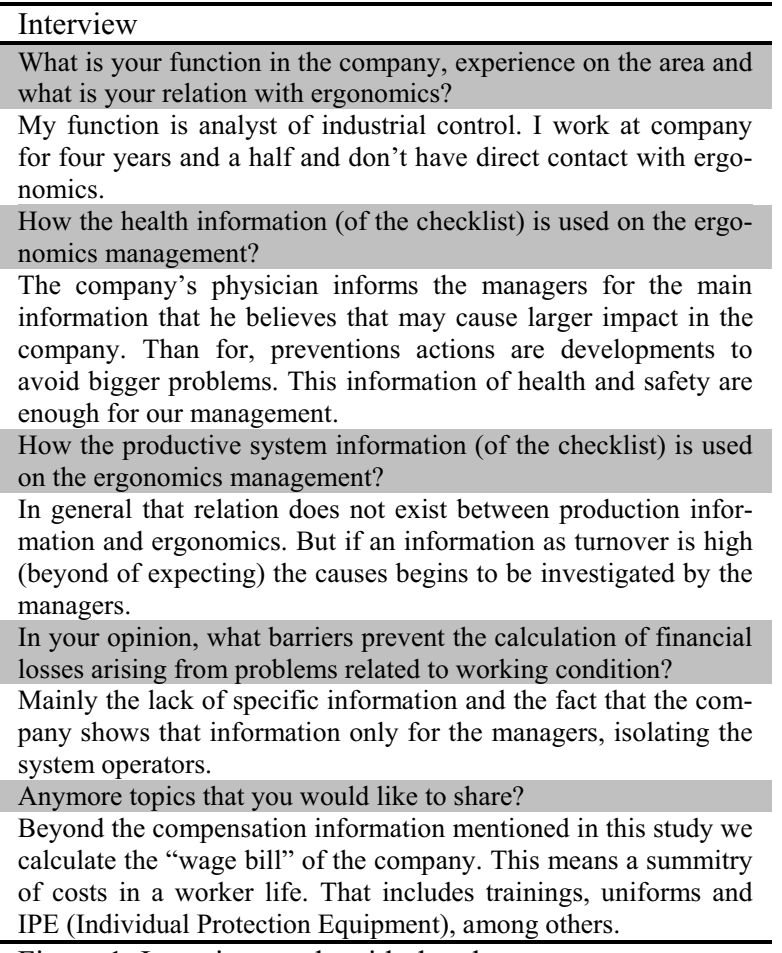

Figure 1. Interview made with the glass company manager. Questions are positioned in the gray areas and answers in the white ones. 
The manager interviewed (Figure 1) has access to the company's information and at the same time administer improvement projects of work conditions. One of the results of this interview indicates that company's culture doesn't believe that ergonomic projects could provide financial benefits what so ever. Therefore the financial information's are not used with this finality.

The results of the checklist are presented in Table 2. The existence or not of each information on the list was marked and a commentary regarding its utilization completes the observation.

The first result that can be seen is that most items of the checklist are available in the company. In addition, an important feature of the information available is that they usually correspond to an entire industry or even the whole plant, not a specific working condition as a job.

\subsection{Paper converting plant}

The research was also deployed in a paper converting plant in Portugal maintaining the same methodology. The paper converter is supplied with paper reels with different diameters and widths, huge number of SKU (Stock Keeping Units) of different paper quali- ties and substances. High degree of automation is present throughout all the plant and a very sophisticated IT System, linking converting processing orders with MRP (Material Replenishment Planning) systems and converting floor level machinery interfaces, guaranties proper workflow control. Paper sheets of different sizes, dully packed in boxes and pallets, are made available for the market (mainly big printers, publishing editors and offices). Automatic downloading of converting machinery settings and the retrieve of production data, rates, efficiencies, hourly output, on line costs, on line inventory and others, is part of the management system.

The checklist applied in the Paper Converter is presented in Table 3. Almost half of the information of the checklist was not found in the converting facility management. Due to the insurance company role, information cost related to accidents and injuries, on a case to case basis, is not monitored. All the other variable and fixed production costs, as well as direct and indirect personnel costs related with normal and extra working hours, with transportation to factory, performance, hiring and training are used.

Table 2.

Results of the glass manufacturer checklist. The numbers in the left represent the information described in Table 1.

\begin{tabular}{|c|c|c|c|}
\hline & YES & $\mathrm{NO}$ & COMMENTS \\
\hline 1 & $\mathrm{X}$ & & $\begin{array}{l}\text { The productivity is measured by the relationship between the weight of glass saleable and the weight of molten glass. This } \\
\text { information represents the productivity as a whole, not possessing specificity of sectors of the company. }\end{array}$ \\
\hline 2 & $\mathrm{X}$ & & Several reasons is registered for lost work days. \\
\hline 3 & $\mathrm{X}$ & & $\begin{array}{l}\text { It is considering one of the principal information, but it depends of series of technical characteristics to relate at the specif- } \\
\text { ic sector. It is quantified by the difference between the total incomes expected and what has been accomplished. }\end{array}$ \\
\hline 4 & $\mathrm{X}$ & & Not separated by sectors. \\
\hline 5 & $\mathrm{X}$ & & Consider all the productive sectors where the extras-hours are needed. \\
\hline 6 & $\mathrm{X}$ & & Only in some tasks. \\
\hline 7 & $\mathrm{X}$ & & $\begin{array}{l}\text { The company does not consider as a relevant problem because absenteeism for other reasons also exists such as personal, } \\
\text { social and no occupational health matters. }\end{array}$ \\
\hline 8 & & $\mathrm{X}$ & The company does not consider a relevant problem. \\
\hline 9 & & $\mathrm{X}$ & The company does not consider a relevant problem. \\
\hline 10 & $\mathrm{X}$ & & $\begin{array}{l}\text { The Medical department of the company control this information and do the management of occupational health based on } \\
\text { the higher impacts observed. }\end{array}$ \\
\hline 11 & $\mathrm{X}$ & & $\begin{array}{l}\text { This is not specifically sectors of the company, however the sectors had some information of internal defects and they are } \\
\text { related to the losses. Beyond that, the company does not relate possible variations of worker performance with work con- } \\
\text { ditions ergonomically unfavorable. }\end{array}$ \\
\hline 12 & $\mathrm{X}$ & & Doesn't have any specificity for the sectors \\
\hline 13 & $\mathrm{X}$ & & $\begin{array}{l}\text { The company does not consider it as a relevant problem. The known costs with health are investments in prevention, } \\
\text { periodical consults and preventive exams. }\end{array}$ \\
\hline 14 & $\mathrm{X}$ & & The company does not consider a relevant problem. \\
\hline 15 & & $\mathrm{X}$ & Not even knowledge by the company. \\
\hline 16 & $\mathrm{X}$ & & Not considered as information related with worker conditions. \\
\hline 17 & $\mathrm{X}$ & & \\
\hline 18 & $\mathrm{X}$ & & Compose de value name "Wage bill". It considers many costs directly relate to the worker in all his company work life. \\
\hline
\end{tabular}


The interview results shown in Figure 2 were made with the factory director who is also the responsible for occupational health and safety in the company. The high level of quantified information available was easily identified, which could become part of a preventive ergonomic management strategy that could lead to a reduction of costs with health, occupational injuries and rework.

Interview
What is your function in the company, experience on the area and
what is your relation with ergonomics?
I'm a company director with 30 years of experience which 20
was on this company. I'm responsible for managing the safety
and health technicians.
How the health information (of the checklist) is used on the ergo-
nomics management?
Preventive and Corrective actions as a result of an accident, or a
near accident situation, are the ones more common in the factory
environment. This kind of information is used on the ergonomics
management only on an indirect way. A Health and Safety plan is
mandatory, all accidents are fully analyzed and authorities are
very keen on inspections. Recent health problems related with
"LMERT" are becoming reason for concern.
How the productive system information (of the checklist) is used
on the ergonomics management?
The information of productive processes has more impact on
safety issues. Ergonomics it's not yet a part of our industrial
culture. I believe that maybe in the automotive sector the ergo-
nomics point of view is different because of the repetitive tasks.
In your opinion, what barriers prevent the calculation of financial
losses arising from problems related to working condition?
Because of the low accidents frequency the impact is also low.
The material responsibility (not civil or criminal responsibility) is
transferred to insurance companies which are starting to get con-
cerned about the situation and their price is getting high. They are
also more rigid on its standards and for the first time inspections
are taking place to investigate the accidents, including the witness
use for serious cases and to prevent fraud. The insurance compa-
ny has the interest of doing risk assessment and even workers
motivation programs to decrease accident rates and insurance
costs.
Anymore topics that you would like to share?
Ergonomis

Ergonomics doesn't belong yet to the industrial management culture in Portugal in most operations. In our case there is few incorrect posture and repetitive tasks on the assembly line, but the risk assessment of these conditions would be interesting as new data.

Figure 2. Description of the interview made with a paper converting company director. Questions are positioned in the gray areas and answers in the white ones.

\section{Discussion}

The objective of this study was to identify if there enough information available to properly assess and quantify the benefits expected from investments on ergonomic projects. The way in which the information is utilized within ergonomics management was also studied.

Information relevant to the use of the data collected and its correlation with occupational conditions were presented through the application of a checklist and an interview on each of the two companies.

One of the difficulties found in the glass manufacturer was the lack of detail regarding the sectors or departments, roles and work conditions. A more accurate calculation could have been expected if the data available was richer in details. Although this can be considered a general problem when talking about cost-benefit quantification the interview with the Brazilian manager shows disbelief on financial results of an ergonomic investment.

The current management culture of the paper converter does not facilitate the integration between ergonomics principles and companies departments such as finance and occupational health and safety. Ergonomics management in Industrial Plants is still at infant stages in Portugal. Although possesses clear and relevant financial information they do not correlate ergonomics as part of the management system. Actually ergonomics it's considered only as a technical and septic science applied for determined segments such as production lines with repetitive tasks. On the other hand, this organization is a global reference for its investments on work conditions improvement and it shows low levels of incidents. This help to build the boundaries for integrating ergonomics as part of the system management. There are also legal implications in Portugal whereby the big organizations tend to pass the material responsibility (not the civil or criminal responsibility) to manage and handle any work related accidents and diseases, cost of hospitals, eventual compensations and others to insurance companies.

The use of a fully integrated ergonomics management system as a preventive measure that aim to provide solutions and preempt answers can become unattractive, although we truly believe to be the most economical and effective exit for a successful organization in Portugal, Brazil or any country with mid to long term commitment with its environment and community. 
Table 3.

Results of the paper manufacturer checklist. The numbers in the left represent the topics described in Table 1

\begin{tabular}{|c|c|c|c|}
\hline & YES & NO & COMMENTS \\
\hline 1 & $\mathrm{X}$ & & $\begin{array}{l}\text { It's based on a shift, daily, month, year, production output, or number of product units delivered to final shipping ware- } \\
\text { house, per number of worked hours, workers in the plant, shift or resource center. As an overall figure could be expressed } \\
\text { in tones achieved per worker. }\end{array}$ \\
\hline 2 & $\mathrm{X}$ & & Related to disease, accidents, maternity and family issues. \\
\hline 3 & $\mathrm{X}$ & & Number of complaints or returns for each 1000 tons sold plus complaints costs. \\
\hline 4 & $\mathrm{X}$ & & Considered low but is known for sector. \\
\hline 5 & $\mathrm{X}$ & & $\begin{array}{l}\text { Calculated by sector as a percentage of total Available Working Time. Absolute number of extra hours per area, with } \\
\text { related costs, are calculated and reported. }\end{array}$ \\
\hline 6 & & $\mathrm{X}$ & \\
\hline 7 & $\mathrm{X}$ & & \\
\hline 8 & $\mathrm{X}$ & & \\
\hline 9 & $\mathrm{X}$ & & Severity and Frequency Index monitored and reported. \\
\hline 10 & $\mathrm{X}$ & & Medical Department reports. \\
\hline 11 & $\mathrm{X}$ & & $\begin{array}{l}\text { Losses cost due to low performance is expressed as costs of complaints, return of products, poor order book, compensa- } \\
\text { tion for late deliveries and others. }\end{array}$ \\
\hline 12 & & $\mathrm{X}$ & \\
\hline 13 & & $\mathrm{X}$ & $\begin{array}{l}\text { The Insurance Company takes care of these costs on a case by case basis and, therefore, this information is not made } \\
\text { available at Sector level to plant supervisors. }\end{array}$ \\
\hline 14 & & $\mathrm{X}$ & This material responsibility is passed to the Insurance Company. \\
\hline 15 & & $\mathrm{X}$ & \\
\hline 16 & $\mathrm{X}$ & & Cost of temporary workers for substitutions of those absent due to illness, injuries or accidents. \\
\hline 17 & & $\mathrm{X}$ & \\
\hline 18 & $\mathrm{X}$ & & \\
\hline
\end{tabular}


Perhaps the great difference between both companies on this study is the maturity stage concerning the use of information on management system. Unfortunately, the lack of an economic justification for ergonomics view is a resemblance among the glass and paper manufacturers. Not to mention the manufacturing industry as a whole.

Nonetheless this is not an issue exclusive to ergonomics but shared by any discipline involved with the production management system [23].

The organization and its management are unaware of the possibility of using the data such as described on this study to justify projects and investments in ergonomics. Some hypotheses to justify the lack of the knowledge states that the deployment of bad ergonomics by unqualified professionals brings the wrong idea that ergonomics are common sense and that decision makers are proactively investing on it because is considered the right thing to do [11].

The level of data available shows that we are able to provide a more accurate representation of the costs involved with occupational issues that could be solved by ergonomics. It is important to mention that the information on this study belongs to the research methodology published internationally and that some are not usually utilized on the management of health, safety or ergonomics, as per case study presented.

\section{Conclusion}

The study presented a case study showing the existence and the use of information to assess the economic benefits of investments in ergonomics projects. It was possible to establish through the data collected that most of the information utilized in ergonomic research are available although its use to justify the implementation of ergonomic measures are unknown by the industrial management consulted. There is a great need to demystify and clarify the use of ergonomics and its economic benefits. Researches must address how to correlate the data and its financial impact on organizations Ergonomics can be considered a positive contributor to not only health and workers wellbeing but also positive return of investment.

\section{References}

[1] A. Aarãs, The impact of ergonomic intervention on individual health and corporate prosperity in a telecommunications environment, Ergonomics 37 (1994), 10, 1679-1696.
[2] L. Abrahamsson, Production economics analysis of investment initiated to improve working environment, Applied Ergonomics 31 (2000), 1-7.

[3] D. Beevis and I.M. Slade, Ergonomics - costs and benefits, Applied Ergonomics 34 (2003), 413-418.

[4] P.J.W. Carrivick, A.H. Lee, K.K.W. Yau, and M.R. Stevenson, Evaluating the effectiveness of a participatory ergonomics approach in reducing the risk and severity of injuries from manual handling, Ergonomics 48 (2005), 8, 907-914.

[5] R. Chokkar, C. Engst, A. Miller, D. Robinson, R.B. Tate, A. Yassi, The three-year economic benefits of a ceiling lift intervention aimed to reduce healthcare worker injuries, Applied Ergonomics 36 (2005), 223-229.

[6] M.T. Driessen, J.R. Anema, K.I. Proper, P.M. Bongers, A.J. van der Beek, Stay@work: participatory ergonomics to prevent low back and neck pain among workers: design of a randomised controlled trial to evaluate the cost-effectiveness, BMC Musculoskeletal Disorders 9 (2008), 145.

[7] A.C. Falck, R. Örtengren, D. Högberg, The impact of poor assembly ergonomics on product quality: a cost-benefit analysis in car manufacturing, Human Factors and Ergonomics in manufacturing \& Service Industries 20 (2010), 1, 24-41.

[8] P.A. Hastings, M. Merriken, W.B. Johnson, An analysis of the costs and benefits of a system for FAA safety inspections, International Journal of Industrial Ergonomics 26 (2000), 231248.

[9] H. Hendrick, Determining the cost-benefits of Applying ergonomics to systems: Some documented "lessons learned", Applied Ergonomics 39 (2008), 418-426.

[10]H. Hendrick, Determining the cost-benefits of ergonomics projects and factors that lead to their success, Applied Ergonomics 34 (2003), 419-427.

[11]H. Hendrick, Good ergonomics is good economics, Proceedings of the Human Factors and Ergonomics Society, 40th Annual Meeting, (1996), Santa Monica, CA.

[12] R. Hughes, N. Nelson, Estimating investment worthiness of an ergonomic intervention for preventing low back pain from a firm's perspective, Applied Ergonomics, 40 (2009), 457-463.

[13] S. Jenkins, J. Rickards, Justifying investments in ergonomics pre-intervention, SELF-ACE CONFERENCE, 3 (2001), 1216.

[14]K. Kemmlert, Economic impact of ergonomic intervention four case studies, Journal of Occupational Rehabilitation, 6 (1996), 1, 17-32.

[15] M.P. Kerr, D.S. Knott, M.A. Moss, C.W. Clegg, R.P. Horton, Assessing the value of human factors initiatives, Applied Ergonomics, 39 (2007), 305-315.

[16]P. Kim, J.A. Hayden, S.A. Mior, The cost-effectiveness of an education program for firefighters: a case study, Journal of Canadian Chiropractic Association, 48 (2004), 1, 13-19.

[17] S. Lahiri, J. Gold, C. Levensteins, Net-cost model for workplace interventions, Journal of Safety Research, 36 (2005), 241-255.

[18] S. Lahiri, P. Markkanen, C. Levenstein, The cost effectiveness of occupational health interventions: preventing occupational back pain, American Journal of Industrial Medicine, 48 (2005), 515-529.

[19] S. Lahiri, J. Gold, C. Levensteins, Estimation of net-costs for prevention of occupational low back pain: three case studies from the US, American Journal of Industrial Medicine, 48 (2005), 530-541.

[20]P. Lanoie, S. Tavenas, Costs and benefits of preventing workplace accidents: the case of participatory ergonomics, Safety Science, 24 (1996), 3, 181-196. 
[21]P. Lanoie, L. Trottier, Costs and benefits of preventing workplace accidents: going from a mechanical to a manual handling system, CIRANO (1995), Montreal.

[22]P.F. Riel, D. Imbeau, The economic evaluation of an ergonomic investment for preventive purposes: a case study, Journal of Safety Research, 28 (1997), 3, 159-176.

[23] W.B. Rouse and K.R. Boff, Assessing cost/benefits of human factors, in: Handbook of human factors and ergonomics, G. Salvendy, 2nd ed, John Wiley \& Sons, Inc., New York, 1997.

[24] M. Rowan, P. Wright, Ergonomics is good for business, Work Study, 43 (1994), 8, 7-12.

[25] S. Schneider, Ergonomic intervention has a return on investment of 17 to 1, Appl. Occup. Environ Hyg, 13 (1998), 4, 212-213.

[26]P.A. Seeley, R.W. Marklin, Business case for implementing two ergonomic interventions at an electric power utility, Applied Ergonomics, 34 (2003), 429-439.

[27]R.N. Sen, P.H.P. Yeow, Cost effectiveness of ergonomic redesign of electronic motherboard, Applied ergonomics, 34 (2003), 453-463.

[28] C.M. Sommerich, Economic analysis for ergonomics programs, in: Occupational Ergonomics: Design and Management of Work Systems, W. Karwowski, W.S. Marras, CRC Press, New York, 2003.

[29]E. Tompa, R. Dolinschi, C. Oliveira, B.C. Amick III, E. Irvin, A systematic review of workplace ergonomic interventions with economic analyses, Journal of Occupational Rehabilitation, nov (2009).

[30]P.H.P. Yeow, R.N. Sen, Productivity and quality improvements, revenue increment, and rejection cost reduction in the manual component insertion lines through the application of ergonomics, International Journal of Industrial Ergonomics, 36 (2006), 367-377. 